\title{
PERSPECTIVAS E DESAFIOS NO DEBATE SOBRE FINANCIAMENTO E GESTÃO DA EDUCAÇÃO: DA CONAE A UM NOVO PNE
}

\author{
Andréa Barbosa Gouveia* \\ ÂNGELO RicARdo DE SOUZA **
}

\begin{abstract}
RESUMO: $\mathrm{O}$ artigo analisa as proposições mais importantes no documento final da CONAE 2010 quanto às questōes do financiamento e da gestão da educação e, de forma complementar, cotejar tal texto com as indicações do Plano Nacional de Educação (PNE, Lei n. 172/2001). A leitura e o confronto de tais proposições buscarão contribuir com um dos desdobramentos objetivados pela própria CONAE, que é o de indicar elementos para um novo PNE. O pano de fundo desta construção colocará em tela uma disputa pelas concepções de educação pública e papel do Estado. Os desafios dessa luta se materializarão na disputa pela consolidação das metas aprovadas na conferência nos espaços da democracia representativa formal brasileira.
\end{abstract}

Palavras-chave: Política educacional. Gestão da educação. Financiamento da educação.

Prospects AND CHALLeNGes IN THE Debate ON FUNDiNG AND ADMINISTRATING EDUCATION: FROM CONAE TO A NEW PNE

ABSTRACT: This paper explores the most important propositions from the final resolution of the 2010 CONAE with regard to education funding and administration. Complementarily, it collates the conference documents with the details of the National Plan for

* Doutora em Educação e professora do Núcleo de Políticas Educacionais e do Programa de PósGraduação em Educação da Universidade Federal do Paraná (UFPr). E-mail: andreabg@ufpr.br

** Doutor em Educação e professor do Núcleo de Políticas Educacionais e do Programa de PósGraduação em Educação da UFPr. E-mail: angelo@ufpr.br 
Perspectivas e desafios no debate sobre financiamento e gestão da educação...

Education (Law n. 172/2001). These propositions were read and compared to contribute to one of the very developments intended by the CONAE: indicating elements for a new National Plan for Education. The background of this construction is a dispute around the conceptions of public education and the role of the State. The challenges of this struggle will be materialized in the quarrel to consolidate the goals indicated by the conference in the spaces of formal representative democracy in Brazil.

Key words: Education policies. Education administration. Education funding.

D esde a aprovação da Constituição de 1988 se passaram 22 anos. Este é um período que deve ser celebrado no Brasil, pois são mais de duas décadas em que temos vivido os desafios de construir um Estado democrático sem a iminência de golpes de Estado, coisa que, ao longo de nossa curta história republicana, é nova. No caso da educação, temos 22 anos de busca pela efetivação do princípio da gestão democrática do ensino público. Este princípio, expresso pela primeira vez no texto constitucional de 1988, é um marco num longo processo de construção de uma concepção igualitária de educação.

Neste processo de construção, Luiz Antonio Cunha chama-nos a atenção para o histórico de conferências realizadas por associações de profissionais da educação, entre 1927 e 1967 (Cunha, 1981); depois, para a realização das Conferências Brasileiras de Educação (CBE), entre 1980 e 1988 (Cunha, 1995); e, finalmente, cabe agregar a estes eventos os Congressos Nacionais de Educação (CONED) nos anos de 1990, que resultaram na proposição do Plano Nacional da Sociedade Brasileira que se tornou um dos documentos-base para o debate sobre a Lei n. $10.172 / 2001 .^{1}$

Finalmente, nos anos 2000, perto de se completar um século que os segmentos ligados à educação pública brasileira reivindicam, de diferentes formas, um campo público de debate sobre a política educacional, chegamos à primeira Conferência Nacional de Educação (CONAE), convocada por uma Comissão Nacional que, pela primeira vez, é composta por representantes do governo federal e por segmentos da sociedade civil organizada, representando desde os movimentos populares até o segmento de mercado da educação. 
Nesse contexto, o tema central da Conferência foi a construção de um Sistema Nacional Articulado de Educação, portanto, a gestão do sistema e, como decorrência da forma federativa do Estado brasileiro, esta articulação depende, de maneira substantiva, dos contornos que o financiamento tem assumido na relação entre os entes responsáveis pela tarefa educacional.

A proposta de um balanço inicial sobre as proposiçóes no âmbito da gestão e do financiamento, no contexto da CONAE, e os desafios para a elaboração de um novo Plano Nacional de Educação (PNE) são, certamente, uma continuidade para este processo, pois o campo de disputa construído na CONAE será agora ampliado e precisará ocupar os espaços formais de elaboração da legislação educacional.

Neste texto, a intenção é analisar as proposições mais importantes no Documento Final da CONAE 2010 e, de forma complementar, cotejar tal texto com as indicaçóes do PNE (Lei n. 10.172/2001). A leitura e o confronto de tais proposiçóes buscarão contribuir com um dos desdobramentos objetivados pela própria CONAE, que é o de indicar elementos para um novo PNE. O pano de fundo desta construção colocará em tela uma disputa pelas concepçóes de educação pública e o papel do Estado, entre outros elementos. Os desafios dessa luta se materializarão na disputa pela consolidação das metas aprovadas na Conferência, por ocasião da discussão de um novo PNE nos espaços da democracia representativa formal brasileira, ou seja, no Congresso Nacional, locus por excelência do conflito em perspectivas divergentes de políticas sociais.

O financiamento da educação na CONAE: desafios para ampliação do investimento

Os debates acerca do financiamento da educação no âmbito da CONAE expressam um amadurecimento das reflexões sobre este tema entre os diferentes segmentos representados na conferência. Não parece ter sido casual que, neste momento, esta questão ocupe um eixo do documento, enquanto, durante o debate do PNE e mesmo na Lei n. 10172/ 2001, o tema do financiamento aparecia articulado ao tema da Gestão do Sistema de Ensino.

Ainda que possamos pensar o financiamento como uma dimensão da gestão, é possível ponderar que, na última década, diferentes 
Perspectivas e desafios no debate sobre financiamento e gestão da educação...

mudanças da política de financiamento da educação básica mobilizaram novos sujeitos para o debate sobre investimentos em educação. Recursos não são mais uma questão dos técnicos em planejamento; são pauta dos sindicatos de trabalhadores da educação, de organizações não governamentais e, certamente, são pauta das diferentes associações de gestores educacionais como, por exemplo, da União Nacional dos Dirigentes $\mathrm{Mu}-$ nicipais da Educação (UNDIME). Ganham, assim, legitimidade a presença do tema e a explicitação das disputas diretamente relacionadas a ele.

Esta ampliação de interlocutores permite retomar uma observação de Melchior (1987, p. 4) acerca da importância da politização do debate sobre os recursos para educação:

A reordenação do sistema de financiamento, tanto público como privado, fazendo-o girar em torno dos valores de liberdade e igualdade, exige uma operacionalização que passa necessariamente pelo político. Inicialmente, de forma estática, estes valores terão que ser inscritos em texto constitucional. Posteriormente, a aplicação dos valores de igualdade, bem como as restriçōes deverão ficar com a representação política, tanto legislativa quanto executiva. Para que essa reordenação possa ser executada, exige-se uma condição básica da representação política: sua legitimidade.

O professor Melchior discutia, naquele momento, a necessidade de retomada do princípio da vinculação constitucional de recursos para educação, no contexto da abertura, e a questão da legitimidade dizia respeito à reconstrução da democracia no país, a partir da instalação da Constituinte. Passados 27 anos da aprovação da Emenda João Calmon, que retomou a vinculação de receitas para a educação, continuamos a afirmar que tornar o sistema de financiamento um instrumento de construção de igualdade para a oferta educacional no país é uma questão da política. Neste sentido, o espaço que a disputa pública por recursos tomou no âmbito da CONAE parece uma notícia alvissareira, que, porém, não diminui a intensidade das disputas por tais recursos.

O eixo do financiamento da educação, uma década depois da proposição e aprovação do PNE, mantém temas bastante comuns, decorrentes da manutenção dos desafios de democratização do sistema escolar brasileiro. As proposiçôes dedicam-se a garantir incremento de condições de financiamento da educação a partir de diferentes subtemáticas: a vinculação de recursos para educação pública; participação da 
União no financiamento da educação; equidade de gastos; o uso dos recursos vinculados; necessidade de uma reforma tributária com justiça social; fiscalização e publicização dos investimentos; política de fundos; integração de políticas sociais; controle sobre a iniciativa privada; autonomia das unidades escolares. Destas, destacaremos algumas para maior aprofundamento, na sequência.

A primeira temática, identificada aqui como "vinculação de recursos", articula vários aspectos que têm relação direta com a necessidade de ampliação de recursos para a educação no país. O campo de forças construído na escolha de delegados para a CONAE, em suas diferentes etapas, ${ }^{2}$ permitiu a retomada de um princípio caro aos defensores da escola pública, qual seja: a garantia da "aplicação dos recursos públicos exclusivamente nas instituições públicas de ensino” (Brasil, 2010, p. 107). Princípio este que havia sido derrotado no trâmite da Constituinte de 1988, para ficarmos na história recente das disputas entre Estado e mercado na educação brasileira.

Esta retomada vem acompanhada de proposições de regulamentação do setor privado e de congelamento, em cinco anos, das matrículas na educação infantil financiadas com recursos do Fundo de Manutenção e Desenvolvimento da Educação Básica e de Valorização dos Profissionais da Educação (FUNDEB), assim como na educação especial (Brasil, 2010), em instituiçôes privadas de diferentes tipos e, a partir daí, a suspensão de recursos para tais instituições. O Documento Final não explicita que os recursos não vinculados ao FUNDEB tampouco deveriam ser destinados à iniciativa privada. Pode-se considerar que esta medida seria a que melhor atenderia ao princípio da exclusividade de verbas públicas para instituiçôes públicas. Entretanto, isso demandaria uma revisão no artigo 213 da Constituição Federal.

Observe-se, ainda, que a retomada do princípio não é coerente em todo o Documento Final. Como expressão da conjuntura política, a objetividade de suspensão de repasse de recursos para instituiçóes privadas na educação básica não manteve a mesma tônica nas metas referentes ao ensino superior, por exemplo. Neste caso, apesar do documento enfatizar a necessidade de ampliação da oferta pública, ao se referir ao Programa Universidade para Todos (PROUNI), o faz sem estabelecer prazo para o congelamento das matrículas subsidiadas ${ }^{3}$ com recursos públicos. 
Perspectivas e desafios no debate sobre financiamento e gestão da educação...

A diferença de tratamento entre os dois níveis de ensino pode ser expressão do estágio em que estamos na oferta de oportunidades de ensino no país. Segundo dados apresentados no próprio Documento Final da CONAE, apenas $12 \%$ da população de 18 a 24 anos encontram-se matriculados em algum curso de graduação (Brasil, 2010). Esta situação promove o encontro dos interesses do mercado em acessar recursos públicos com o interesse dos usuários em acessar oportunidades de cursar o ensino superior.

Este movimento de inclusão de usuários no sistema educacional de forma subsidiada não é exclusividade do ensino superior. A expansão das vagas filantrópicas, confessionais ou comunitárias na educação especial e na educação infantil tem o mesmo efeito. Chama-se a atenção aqui para este processo, pois, se o campo de forças presente na etapa nacional da CONAE permitiu a retomada do princípio da exclusividade de recursos públicos para a escola pública, isso não se fez como consenso. As muitas experiências de subvenção social para instituições privadas ofertarem a educação têm contribuído para construir o que Oliveira (1999, p. 57) chama de uma "experiência subjetiva de desnecessidade aparente do público". Assim, se a maioria dos segmentos da CONAE teve acordo para explicitar prazos para o fim de subvençôes sociais na educação básica, por outro lado, já não se manteve o mesmo peso para o caso do ensino superior. $\mathrm{O}$ que poderemos esperar quando essa proposição sair do âmbito da conferência e ganhar outras esferas de disputas públicas, numa sociedade cada vez mais marcada por experiências subjetivas de privatização da vida cotidiana?

Para além da definição de quais instituiçōes devem ser mantidas com recursos públicos, esteve na pauta da CONAE, de maneira contundente, a necessidade de ampliação dos recursos. O PNE aprovado pela Lei n. 10.172/2001 teve a meta referente à ampliação de recursos vetada pelo então presidente Fernando Henrique Cardoso, e este veto nunca foi derrubado no Congresso Nacional. Ainda que no texto da lei ${ }^{4}$ tenha permanecido um compromisso tênue com a ampliação de recursos expresso na afirmação "garantir, entre as metas dos planos plurianuais vigentes nos próximos dez anos, a previsão do suporte financeiro às metas constantes deste PNE" (Brasil, 2001, p. 94), o texto final da CONAE expressa, de maneira bem mais consistente, a preocupação dos diferentes segmentos ali representados com a necessidade de ampliação de recursos: 
Ampliar o investimento em educação pública em relação ao PIB, na proporção de, no mínimo, $1 \%$ ao ano, de forma a atingir, no mínimo, $7 \%$ do PIB até 2011 e, no mínimo, 10\% do PIB até 2014, respeitando a vinculação de receitas à educação definidas e incluindo, de forma adequada, todos os tributos (impostos, taxas e contribuiçôes). (Brasil, 2010, p. 110)

Garantir o aumento dos recursos da educação de $18 \%$ para, no mínimo, $25 \%$ da União e de $25 \%$ para, no mínimo, 30\% (de estados, DF e municípios) não só da receita de impostos, mas adicionando-se, de forma adequada, percentuais das taxas e contribuições sociais para investimento em manutenção e desenvolvimento do ensino público. (Idem, ibid., p. 111)

Essa diferença de ênfase entre o PNE e o documento da CONAE tem pelo menos duas explicaçóes. Primeiro, a questão da falta de recursos para garantir o cumprimento das metas do PNE estava bastante fundamentada no Projeto de Lei n. 4.155/98 apresentado como proposta da sociedade civil. $\mathrm{O}$ que explica, em parte, o veto àquela meta é a hegemonia de uma concepção de política educacional, cujo diagnóstico dos problemas educacionais sustentava-se na tese de que estes problemas eram decorrentes da qualidade dos gastos e não da quantidade de recursos. Isso era um diagnóstico presente não apenas no discurso da política educacional brasileira, mas também um dos eixos das reformas educacionais em curso na America Latina, ao longo da década de 1990 (Casassus, 2001).

Se a hegemonia de uma corrente de pensamento explica a não priorização de metas de elevação do investimento para dar lugar à primazia de melhorias apenas no âmbito da gestão dos recursos. O segundo elemento que ajuda a explicar a necessária retomada de metas de ampliação significativa de recursos no contexto da CONAE é a manutenção de uma dívida educacional do país, resultado de um patamar constante de investimento do PIB que não permite afirmar que a educação tenha se convertido em uma prioridade do Estado brasileiro.

Ainda neste tema da vinculação de recursos, o Documento Final da CONAE apresenta a proposição de fontes novas de recursos decorrentes de atividades de produção energética no país. Nesta direção encontramse duas proposiçôes: a primeira, relativa à vinculação de " $50 \%$ dos créditos advindos do pagamento de royalties decorrentes de atividades de produção energética (extração, tratamento, armazenagem e refinamento de 
Perspectivas e desafios no debate sobre financiamento e gestão da educação...

hidrocarbonetos) à manutenção e desenvolvimento do ensino (MDE)”, e a segunda, referente aos recursos especificamente do Fundo Social advindos da exploração da camada pré-sal, que "devem ter uma destinação na ordem de $50 \%$ de suas receitas para a educação, tendo, desse modo, vinculação imediata ao orçamento do MEC, ou seja, não devem passar por deliberação do Comitê Gestor do Fundo Social" (Brasil, 2010, p. 118). Cabe lembrar que tal expediente já foi previsto na legislação brasileira quando da criação da Petrobrás. Pela Lei n. 2.004 de 1953, uma parte dos royalties do óleo extraído de plataformas continentais deveria compor um Fundo de Mineração e outra parte seria destinada ao Ministério da Educação, mas isso foi abandonado na década de 1970 (Melchior, 1987). Portanto, não se trata de uma ideia nova, mas de uma proposição que, positivamente, pode colocar recursos novos na expansão da oferta educacional, ainda que demande um grau de mobilização social para aprovação desta norma no Congresso Nacional muito além de todos os esforços de construção da CONAE.

A segunda grande temática do financiamento da educação na CONAE refere-se, de certa forma, à questão do pacto federativo brasileiro e à histórica ausência da União na garantia da educação básica. Dessa forma, o documento afirma:

Considerando que cabe à União liderar o esforço em aumentar o investimento em educação em relação ao PIB, há que se estabelecer estratégias nacionais, compreendendo-se a ação conjunta da própria União, dos estados, DF e municípios. Este esforço deve ser proporcional à respectiva participação de cada um na arrecadação nacional, levando-se em conta as responsabilidades constitucionais de cada ente da Federação. Portanto, é preciso definir o papel da União em todas as modalidades e níveis de ensino (educação básica e ensino superior), e não somente os papéis dos estados e municípios. (Brasil, 2010, p. 108)

Para que a União possa liderar este esforço, há pelo menos duas proposições substantivas no documento: a conversão do FUNDEB em um fundo nacional que tome "como referência o maior per capita existente no país, com o objetivo de unificar o valor aluno/a por ano executado no Brasil, acabando com as desigualdades por estado" (idem, ibid., p. 113); a definição do custo aluno-qualidade (CAQ) de maneira democrática, no prazo de um ano, possibilitando o estabelecimento de uma referência básica de condições de qualidade para as escolas, cabendo "à 
União a complementação de recursos financeiros a todos os estados e aos municípios que não conseguirem atingir o valor do CAQ" (p. 105).

A proposição do $\mathrm{CAQ}$ como instrumento de combate às desigualdades crônicas do sistema educacional brasileiro não é apenas de ampliação do papel da União, mas aparece de maneira transversal, ao longo do Documento Final, como condição para a construção de equidade. A força que o debate do $\mathrm{CAQ}^{5}$ tomou ao longo da conferência precisa, novamente, ser destacada, pois, durante a CONAE, o Conselho Nacional de Educação ( $\mathrm{CNE}$ ) apresentou uma proposta de parecer que estabelece normas para aplicação do inciso IX do artigo $4^{\circ}$, da Lei n. 9.394/96 (LDB), que trata dos padrōes mínimos de qualidade de ensino para a educação básica pública. Este parecer, na prática, determina parâmetros para o CAQ e foi aprovado no CNE em 5 de maio de 2010 e, até julho, ainda aguardava homologação do ministro. Tal documento não é decorrente da CONAE, mas do processo de discussão da temática do financiamento que tanto permitiu que este tema fosse um eixo da CONAE, quanto gerou esta iniciativa do CNE. Esta definição tem impactos importantes em termos de número de alunos por turma, equipamentos, profissionais, material pedagógico, nas diferentes etapas e modalidades da educação básica. Portanto, tem impactos nas condiçôes de financiamento e pode ser um primeiro elemento, pós-CONAE, para a implementação das metas definidas na conferência, ou, no caso da não homologação do referido parecer, este pode ser um primeiro ponto em que veremos novas tensões para a realização de tais metas.

Os demais pontos discutidos na conferência e expressos no Documento Final são demonstrativo de certo refinamento do debate sobre financiamento entre os representantes dos diferentes segmentos que compuseram a CONAE. Em termos de uso dos recursos vinculados, retoma-se a necessidade de retirar as despesas com aposentadorias e pensões da conta dos recursos vinculados à MDE, garantindo paridade entre aposentados/as e ativos/as; e ampliação da definição de metas de investimento na oferta de educação infantil, ensino médio, profissional, ensino superior e no transporte escolar, tema bastante problemático nas relações de cooperação entre estados e municípios no país.

A ênfase numa gestão com vistas à superação das desigualdades aparece também nas metas relativas à manutenção da política de fundos. Neste momento específico, trata-se de problematizar o 
Perspectivas e desafios no debate sobre financiamento e gestão da educação...

funcionamento do Fundeb. O Documento Final da CONAE é bastante mais extenso nesta questão do que a Lei n. 10.172/2001 e, certamente, contribui para isto: a) o acúmulo de experiência de diferentes segmentos da sociedade civil que participam dos conselhos de acompanhamento e controle social (CACS); b) a prática dos gestores públicos com o funcionamento e os impasses da política de fundos e; c) o conhecimento sistematizado sobre estas diferentes experiências (Pinto, 2007; Oliveira, 2003; Davies, 2008). Entre as proposições de mudanças no funcionamento do FUNDEB, estão a necessidade de rever a ideia de balizas para os fatores de ponderação no âmbito do fundo; a proposição de eliminação de barreira de expansão de recursos para a educação de jovens e adultos, e a já destacada proposta de converter o fundo em um mecanismo nacional. Estas proposições, ainda que pareçam técnicas, são eminentemente políticas, no sentido de reafirmar as bases de um sistema nacional articulado que tenha realmente condições de universalizar educação de qualidade.

O tema do controle social sobre o uso dos recursos públicos é abrangente no documento da CONAE e reflete tanto as preocupações com a responsabilização dos gestores públicos com relação ao cumprimento da legislação, quanto a necessidade de democratização dos espaços de controle social e a necessidade de formação dos jovens para a questão tributária. Esta, certamente, é uma face muito articulada com a concepção de gestão do sistema. Dessa forma, vale a pena passar à segunda temática.

A gestão da educação na CONAE: desafios para a democratização

O PNE em vigência (Lei n. 10.172/2001) trata das questôes afetas à gestão da educação e da escola de maneira articulada ao financiamento. Na CONAE, estes são aspectos tratados em momentos específicos e com focos também diversos. Enquanto a discussão sobre o financiamento da educação, como vimos, é mais articulada à organização dos sistemas de ensino, a gestão é tratada de maneira mais focalizada nas instituições educacionais (de educação básica ou superior), ou pelo menos aparenta sempre ter a escola como a razão da (nova) gestão. Assim, a complementaridade que existia entre os dois elementos no PNE diminui um pouco no texto final da CONAE. 
De toda forma, há várias interfaces importantes a serem observadas entre aquele plano e as resoluções desta conferência, no que tange às propostas para a gestão da educação e das escolas, de sorte a se averiguar os aspectos nos quais parece haver avanços e aqueles ainda carentes de maior substância.

O Documento Final da CONAE 2010 avança quando explicita uma concepção de gestão democrática, vinculada à ampliação do direito à educação, inclusão, qualidade social e avaliação emancipatória. Ainda que se trate de um texto pouco objetivo sobre o que isso tudo de fato significará em termos de procedimentos de políticas públicas para a educação, é importante que o documento tenha "demarcado território" sobre o que os conferencistas compreendem como elementos necessários para a democratização da (gestão da) educação. Ademais, o texto reclama pela necessidade de se regulamentar o artigo $206 \mathrm{da}$ Constituição Federal, em particular no item sobre a gestão democrática, apontando, inclusive, para a sua extensão ao segmento privado da educação, quando couber.

No que tange à gestão dos sistemas de ensino, como mencionado, o Documento Final não promove discussões mais aprofundadas. Todavia, destaca a importância de se regulamentar o princípio do regime de colaboração entre União, estados, Distrito Federal e municípios, uma vez que, na leitura que faz da temática, identifica algumas das razões pelas quais tal regime não se efetiva (ausência de diretrizes educacionais comuns, ausência de regulamentação sobre as responsabilidades específicas de cada ente federado, entre outras). O PNE apontava para a necessidade de aperfeiçoamento do regime de colaboração e também destacava a necessidade de se melhor definir as responsabilidades de cada ente federado (Brasil, 2001, Anexo 11.3.2, Metas 19 e 20).

Ainda no que se refere à gestão dos sistemas de ensino, o Documento Final da CONAE avança em relação ao PNE ao consagrar o modelo das conferências com a participação da sociedade civil e do Estado, e o faz com a proposição da realização de conferências municipais, estaduais/distrital e nacional de educação, com ocorrência em no máximo quatro anos (Brasil, 2010). Enquanto o PNE apontava para a necessidade de se incentivar os municípios a organizarem seus próprios conselhos municipais de educação e, junto com os estados, a produzirem os seus planos de educação, o Documento Final da CONAE reconhece que 
Perspectivas e desafios no debate sobre financiamento e gestão da educação...

os esforços para a ampliação da democratização da gestão educacional demandam uma articulação mais efetiva:

Para a efetivação dessa concepção ampla, faz-se necessário garantir espaços articulados de decisão e deliberação coletivas para a educação nacional: Fórum Nacional de Educação, fóruns estaduais, municipais e distrital de educação, Conferência Nacional de Educação, Conselho Nacional de Educação (CNE), conselhos estaduais (CEE) e municipais (CME); órgãos colegiados das instituições de educação superior e conselhos escolares. Situam-se, como espaços de definição de políticas de Estado, o Plano Nacional de Educação, os planos municipais e estaduais de educação e, no âmbito das instituições educativas, a construção coletiva de planos de desenvolvimento institucionais e de projetos político-pedagógicos. (Brasil, 2010, p. 44)

Acerca da gestão escolar, o Documento Final busca ser mais objetivo e transformar os princípios democráticos em proposiçōes mais procedimentais. A começar pelo reconhecimento da necessidade de se garantir que em todas as escolas públicas, de todos os níveis, etapas ou modalidades, os dirigentes sejam escolhidos pelas comunidades por meio do voto direto. Tal debate, polêmico como sempre, encontra problemas porque implica definir se a direção escolar é um cargo público ou uma função pública. Se entendida como cargo (de carreira), a Constituição Federal não permite outra forma de provimento que não o concurso público (salvo os casos tipificados na própria Constituição, no artigo 37). Todavia, parece-nos que tal discussão poderia tomar outro rumo, inclusive na superação da inconstitucionalidade atualmente arguida contra as legislaçôes que existem e que regulamentam procedimentos de eleições para direção escolar, caso se considere que, ao menos na educação básica, trata-se de uma função a ser desempenhada pelos detentores do cargo público de professor/docente/educador/pedagogo; porque, assim, tem-se a possibilidade de eleição de educadores para assumirem a direção escolar, os quais desempenharão temporariamente esta função (durante um mandato ou dois) e, depois, retornarão à sua função de origem, atrelada ao cargo para o qual foram concursados. A CONAE, todavia, não adentrou em tal discussão e, considerando as dificuldades que projetos de lei em trâmite no Senado Federal ${ }^{6}$ têm encontrado, parece difícil que tal matéria avance.

A autonomia das escolas de educação básica é outro aspecto abordado em ambos os documentos. Enquanto o PNE observava a necessidade 
de se ampliar a autonomia das instituiçóes, de maneira muito articulada aos eixos das reformas educacionais iniciadas no país na década de 1990 (por meio da descentralização, com ênfase na autonomia administrativa e financeira), o Documento Final da CONAE faz outra leitura da autonomia. Sem deixar de apontar para a sua ampliação, e ratificando as noções de autonomia colocadas na LDB (pedagógica, administrativa e de gestão financeira), a CONAE articula a autonomia escolar com os objetivos maiores da educação, como a representatividade social e a formação da cidadania, assim como a superação do autoritarismo e do individualismo.

O Documento Final também apresenta outra abordagem de uma questão sempre preocupante na organização e gestão da educação: as condições de qualidade. Enquanto o PNE focalizava suas metas na necessidade de se ampliar as condições materiais, especialmente de informatização das escolas e redes de ensino, assim como de suporte ao planejamento e avaliação, a CONAE elenca uma variedade de elementos que intervêm na qualidade educacional, organizados em quatro planos: plano do sistema (bibliotecas, condições materiais das escolas, laboratórios, salas equipadas etc.); plano da instituição educativa (projeto pedagógico, disponibilidade de docentes para todas as atividades curriculares, mecanismos de participação da comunidade e dos estudantes na organização escolar etc.); plano do/a professor/a (formação adequada às funções, qualificação constante, salário e carreira docente que valorizem o professor etc.); plano do/a estudante (condiçóes de acesso, permanência e aprendizagem, condiçôes que respeitem as diversidades do grupo discente, condiçóes de acessibilidade etc.). A CONAE aponta, assim, para o entendimento de que a gestão da instituição educacional pode auxiliar a (re)definir rumos importantes e alterar o curso e os resultados do trabalho escolar, mas reconhece que há problemas estruturais que exigem mais do que a qualificação da equipe gestora para serem superados.

Por fim, o documento da CONAE produz uma crítica ao modelo de avaliação adotado pelo país ao longo das duas últimas décadas, reconhecendo que se trata de característica evidente de uma política de regulação articulada aos objetivos definidos pelas reformas educacionais implementadas no país:

As reformas políticas e educacionais, no Brasil, orientaram-se pelo eixo descentralizante e, ao mesmo tempo, regulador, tendo o setor educacional assumido o discurso da modernização, da gerência, da descentralização, da 
Perspectivas e desafios no debate sobre financiamento e gestão da educação...

autonomia escolar, da competitividade, da produtividade, da eficiência e da qualidade dos sistemas educativos, na ótica do desenvolvimento de competências para atender às novas exigências no campo do trabalho. (Brasil, 2010, p. 52)

Contudo, o documento reconhece que há avanços trazidos pelo sistema de avaliação, mas propõe que, para além da aferição do rendimento escolar, a avaliação educacional deve considerar outras variáveis que, sabidamente, têm impacto na aprendizagem, como a desigualdade social e econômica nas práticas pedagógicas; a formação e qualificação, bem como os salários e a carreira docentes; as condiçôes materiais e físicas das escolas; a gestão democrática; enfim, um conjunto amplo de aspectos que interferem (a favor ou contrariamente) no alcance dos objetivos educacionais. Mesmo estes objetivos, de resto, são desconsiderados, em alguma proporção, na avaliação estandardizada, uma vez que, contraditoriamente, os docentes nas escolas têm a tarefa de elaborar a proposta pedagógica de cada instituição, mas tal referencial não é considerado no processo avaliativo externo. Assim, o documento da CONAE reclama por uma avaliação que não seja focada no ranking e na classificação, mas na detecção e apontamento de alternativas para a solução de problemas. A melhor alternativa, segundo os conferencistas, passa pela articulação da avaliação com a democracia, incluindo os sujeitos avaliados (alunos e docentes) como (auto)avaliadores.

Financiamento e gestão da educação: as possibilidades de um Sistema Nacional Articulado de Educação e os desafios para um novo Plano Nacional de Educação

Talvez, a principal dificuldade para a construção do Sistema Nacional Articulado de Educação esteja ancorada no Pacto Federativo (ou na sua indefinição). $\mathrm{O}$ regime de colaboração, definido pelo artigo 211 da Constituiçāo Federal, precisa ser repensado para se evitar concorrência e sobreposição de responsabilidades. O Documento Final da CONAE não demonstra ter lidado de maneira objetiva quanto a esse aspecto nos campos do financiamento e da gestão da educação, pois, mesmo que aponte para a ampliação do investimento de todos os entes federados e para a constituição/fortalecimento de mecanismos de controle social e de democratização da gestão da educação nos municípios, 
estados e na União, não indica alternativas concretas para a efetivação de um sistema realmente articulado.

Todavia, um dos objetivos que acompanhou todo o processo de construção da CONAE foi o de projeção de diagnóstico e metas para um novo PNE para a próxima década, uma vez que a Lei n. 10.172/2001 terá seu ciclo completo no final de 2010, ainda que sem atingir o conjunto de metas ali proposto. O Documento Final da CONAE não é ainda um esboço de PNE, mas um instrumento importante de redefinição da política educacional, contendo assim, certamente, elementos para a empreitada de um novo Plano.

A dimensão de uma bússola para a redefinição da política educacional e as dificuldades daí decorrentes têm relação com o fato de que vários aspectos aprovados na conferência demandam revisão constitucional, mais que um novo Plano plurianual/decenal. Este é o caso, por exemplo, das proposições de ampliação do percentual vinculado de recursos à MDE, de ampliação das fontes desta vinculação e da reforma tributária.

Outros aspectos poderão ser resolvidos por legislação complementar. Ainda que tal procedimento seja mais simples que revisóes constitucionais, do ponto de vista procedimental, não o são, necessariamente, do ponto de vista político e, nesse sentido, temos como desafios: a regulamentação do regime de colaboração, a definição de parâmetros nacionais de custo aluno-qualidade (CAQ) e a definição de regras para escolha de dirigentes escolares.

Finalmente, o documento oferece elementos de diagnóstico e proposição de metas substantivas para um novo PNE expressos em proposições relativas ao incremento das condições de gestão do financiamento ou, por exemplo, de consolidação da autonomia das instituições educacionais. $\mathrm{O}$ quadro 1, em anexo ao final do artigo, apresenta um mapeamento inicial destas metas e do tipo de instrumento que a sua conversão em política educacional pode demandar. Todavia, não são objeto de discussão deste texto as implicaçóes políticas que cada uma dessas formas certamente exigirá na dinâmica social.

Finalmente, não há dúvidas de que o Documento Final da CONAE pode ser um instrumento consistente para a formulação da política educacional a curto e médio prazos. Entretanto, o desafio político que se apresenta é tão rico quanto as formulaçôes ali contidas, posto que se deve 
Perspectivas e desafios no debate sobre financiamento e gestão da educação...

considerar que a arena pública de discussão que possibilitou o desenho de tal documento foi, pela primeira vez, composta por segmentos por vezes antagônicos no cenário educacional brasileiro. Entretanto, nem todos estes segmentos ocuparam com força total o campo de disputas. A experiência anterior de defesa, nas instâncias representativas, de um documento bastante coeso, como a proposta de Plano Nacional de Educação da Sociedade Brasileira, mostrou as dificuldades de enfrentamentos entre concepções de educação e de Estado no âmbito do Congresso Nacional. Agora, há um documento com uma nova legitimidade para voltarmos à arena legislativa. Entretanto, este processo demandará novamente um alto nível de mobilização dos interessados em efetivar os avanços no sentido de uma educação pública, gratuita, laica e de qualidade para todos.

\section{Recebido e aprovado em agosto de 2010.}

\section{Notas}

1. Cabe lembrar que o Plano Nacional proposto pelo MEC foi apensado ao projeto elaborado nos CONED, o qual foi protocolado anteriormente pelo deputado federal Ivan Valente e recebeu o número $4.155 / 98$.

2. A CONAE nacional foi antecedida por conferências estaduais e conferências municipais ou intermunicipais. Esta construção implicou muitas negociações entre os segmentos acerca do número de representantes que cada um teria no âmbito nacional. A composição das delegações guardou uma relação geral com a distribuição da matrícula no Brasil.

3. O prouni financia bolsas integrais e parciais em instituiçôes privadas de ensino superior.

4. A meta aprovada na Lei n. 10.172 e vetada pelo Presidente Fernando Henrique Cardoso era explícita quanto à forma de ampliação dos recursos: "Elevação, na década, através de esforço conjunto da União, estados, Distrito Federal e municípios, do percentual de gastos públicos em relação ao PIB, aplicados em educação, para atingir o mínimo de 7\%. Para tanto, os recursos devem ser ampliados, anualmente, à razão de $0,5 \%$ do PIB, nos quatro primeiros anos do Plano e de 0,6\% no quinto ano" (Brasil, 2001, p. 93).

5. Para um aprofundamento sobre o CAQ, consultar Pinto e Carrera (2007).

6. Projeto de Lei do Senado (n. 344 de 2007), de autoria da senadora Ideli Salvatti, que recebeu avaliação de inconstitucionalidade na sua primeira apreciação na Comissão de Constituição e Justiça do Senado.

\section{Referências}

BRASIL. Lei n. 10.172, de 9 de janeiro de 2001. Aprova o Plano Nacional de Educação e dá outras providências. Diário Oficial da 
União, Brasília, DF, 10 jan. 2001. Seção 1, p.01. Disponível em: http://www.planalto.gov.br/ccivil_03/leis/leis_2001/110172.htm

CASASSUS, J. A reforma educacional na América Latina no contexto de globalização. Cadernos de Pesquisa, São Paulo, n. 114, p. 7-28, nov. 2001 .

CONFERÊNCIA NACIONAL DE EDUCAÇÃO (CONAE), 2010, Brasília, DF. Construindo o Sistema Nacional Articulado de Educação: o Plano Nacional de Educação, diretrizes e estratégias; Documento Final. Brasília, DF: MEC, 2010 Disponível em: <http://conae.mec.gov.br/ images/stories/pdf/pdf/documetos/documento_final.pdf>

CUNHA, L.A. A organização do campo educacional: as conferências de educação. Educação \& Sociedade, Campinas, n. 9, p. 5-48, maio 1981 .

CUNHA, L.A. Educação, Estado e democracia no Brasil. São Paulo: Cortez; Niterói: UfF, 1995.

DAVIES, N. FUNDEB: a redenção da educação básica? Campinas: Autores Associados, 2008.

MELCHIOR, J.C.A. O financiamento da educação no Brasil. São Paulo: EPU, 1987.

OLIVEIRA, F. Privatização do público, destituição da fala e anulação da política: o totalitarismo neoliberal. In: Paoli, M.C.; Oliveira, F. (Org.). Os sentidos da democracia: políticas do dissenso e hegemonia global. Petrópolis: Vozes; Brasília, DF: NEDIC, 1999. p. 55-81.

OLIVEIRA, R.P. Uma dimensão avaliativa do FUNDEF: a desigualdade regional. Educar em Revista, Curitiba, n. 22, p. 139-151, 2003.

PINTO, J.M.R. A política recente de fundos para o financiamento da educação e seus efeitos no pacto federativo. Educação \& Sociedade, Campinas, v. 28, n. 100, p. 877-897, 2007.

PINTO, J.M.R.; CARREIRA, D. Custo aluno-qualidade inicial: rumo à educação pública de qualidade no Brasil. São Paulo: Global, 2007. v. 1 . 


\section{Quadro 1}

Documento Final da CONAE 2010 - temas escolhidos

\begin{tabular}{|c|c|c|}
\hline Tema & CONAE & Forma \\
\hline Financiamento & Financiamento e controle social & \\
\hline \multirow{3}{*}{$\begin{array}{l}\text { Vinculação de } \\
\text { recursos }\end{array}$} & Fim da LRF na educação e da DRU & Reforma Constitucional \\
\hline & $\begin{array}{l}\text { Ampliação dos recursos vinculados: percentual da } \\
\text { receita e relação com o PIB }\end{array}$ & Reforma Constitucional \\
\hline & $\begin{array}{l}\text { Novos recursos para educação: royalties e recursos do } \\
\text { Pré-Sal. }\end{array}$ & Lei específica \\
\hline \multirow{6}{*}{ Uso dos recursos } & Revisar as restriçōes às matrículas em EJA no FUNDEB & Meta novo PNE \\
\hline & Financiar em regime de colaboração o transporte escolar & Meta novo PNE \\
\hline & $\begin{array}{l}\text { Ampliação da oferta e definiçóes de condiçōes de } \\
\text { financiamento }\end{array}$ & Meta novo PNE \\
\hline & $\begin{array}{l}\text { Ampliar e consolidar as políticas de educação } \\
\text { profissional }\end{array}$ & Meta novo PNE \\
\hline & $\begin{array}{l}\text { Suspensão do repasse de recursos públicos para } \\
\text { instituiçōes privadas de educação infantil com } \\
\text { correspondente ampliação da oferta pública }\end{array}$ & Meta novo PNE \\
\hline & $\begin{array}{l}\text { Retirar as despesas com aposentadoria e pensōes dos } \\
\text { recursos vinculados à MDE }\end{array}$ & Lei específica \\
\hline Reforma tributária & Aprovar reforma tributária transparente em 3 anos & Reforma Constitucional \\
\hline $\begin{array}{l}\text { Publicização dos } \\
\text { investimentos }\end{array}$ & $\begin{array}{l}\text { Criar instrumentos que promovam a transparência na } \\
\text { utilização dos recursos públicos e sua divulgaçáo pelos } \\
\text { sistemas de ensino e pelas escolas, para toda a } \\
\text { comunidade local e escolar }\end{array}$ & Meta novo PNE \\
\hline \multirow{4}{*}{ Política de fundos } & $\begin{array}{l}\text { Tornar o FUNDEB um fundo nacional, tendo como } \\
\text { valor aluno-ano um CAQ nacional }\end{array}$ & Reforma Constitucional \\
\hline & Consolidar o FUNDEB & Meta novo PNE \\
\hline & Retirar sistemas de baliza & Meta novo PNE \\
\hline & $\begin{array}{l}\text { Considerar o custo aluno real na distribuição dos } \\
\text { recursos }\end{array}$ & Meta novo PNE \\
\hline Participação da União & $\begin{array}{l}\text { Ampliação do esforço da União no financiamento da } \\
\text { educação }\end{array}$ & Meta novo PNE \\
\hline Integração de políticas & Programas de renda mínima & Meta novo PNE \\
\hline \multirow{2}{*}{ Iniciativa privada } & Regulamentação do ensino privado & Lei específica \\
\hline & Extinguir repasse de recursos para iniciativa privada. & Reforma Constitucional \\
\hline
\end{tabular}




\begin{tabular}{|c|c|c|}
\hline \multirow{5}{*}{ Fiscalização } & $\begin{array}{l}\text { Efetivar a responsabilização administrativa e fiscal dos } \\
\text { gestores públicos que não cumpram as normas de } \\
\text { vinculação de recursos à MDE }\end{array}$ & Meta novo PNE \\
\hline & Fortalecer os CACS & Meta novo PNE \\
\hline & Aperfeiçoar os mecanismos de fiscalização & Meta novo PNE \\
\hline & Dar publicidade aos recursos da educação & Meta novo PNE \\
\hline & Educação fiscal nas escolas & Meta novo PNE \\
\hline Equidade de gastos & $\begin{array}{l}\text { Definição do custo aluno-qualidade no prazo de um ano } \\
\text { a partir da CONAE }\end{array}$ & Meta novo PNE \\
\hline Gestão & $\begin{array}{l}\text { Qualidade da educação, gestão democrática e } \\
\text { avaliação }\end{array}$ & \\
\hline Concepção de gestão & $\begin{array}{l}\text { Direito à educação, inclusão, qualidade social, avaliação } \\
\text { emancipatória e gestão democrática }\end{array}$ & Meta novo PNE \\
\hline $\begin{array}{l}\text { Regime de } \\
\text { colaboração }\end{array}$ & $\begin{array}{l}\text { Necessidade de regulamentação do princípio } \\
\text { constitucional }\end{array}$ & Meta novo PNE \\
\hline $\begin{array}{l}\text { GD/Conferências de } \\
\text { Educação }\end{array}$ & $\begin{array}{l}\text { Municipais, Estaduais e Nacional, com ocorrência de } \\
\text { até } 4 \text { anos }\end{array}$ & Meta novo PNE \\
\hline $\begin{array}{l}\text { GD/Conselhos } \\
\text { Municipais }\end{array}$ & $\begin{array}{l}\text { Garantia de constituição de conselhos municipais como } \\
\text { parte da estrutura de gestão do sistema de ensino, } \\
\text { portanto como órgãos de Estado }\end{array}$ & Meta novo PNE \\
\hline GD/Regulamentação & $\begin{array}{l}\text { Definir em lei nacional a regulamentação do artigo } 206 \\
\text { da Constituição Federal, sobre a GD, que deve ser } \\
\text { estendida, guardadas as proporções, à educação privada }\end{array}$ & $\begin{array}{l}\text { Reforma constitucional ou } \\
\text { Lei específica }\end{array}$ \\
\hline GD/Planos & $\begin{array}{l}\text { Elaborar planos municipais e estaduais e o novo PNE, } \\
\text { com a mais ampla participação da sociedade }\end{array}$ & Meta novo PNE \\
\hline $\begin{array}{l}\text { GD/autonomia das } \\
\text { unidades escolares }\end{array}$ & $\begin{array}{l}\text { Reforça o conceito de autonomia presente na LDB, mas } \\
\text { amplia ao articular a autonomia com os objetivos } \\
\text { maiores da educação escolar }\end{array}$ & Meta novo PNE \\
\hline $\begin{array}{l}\text { GD/Dirigentes } \\
\text { escolares }\end{array}$ & Eleiçôes diretas para diretor e reitor & $\begin{array}{l}\text { Lei específica e Meta novo } \\
\text { PNE }\end{array}$ \\
\hline $\begin{array}{l}\text { Modernização e } \\
\text { Qualidade }\end{array}$ & $\begin{array}{l}\text { As relações entre número de estudantes por turma, } \\
\text { estudantes por docente e estudantes por funcionário/a } \\
\text { técnico/a-administrativo/a são aspectos/condições } \\
\text { relevantes para a qualidade da educação, uma vez que } \\
\text { melhores médias dessas importantes relações são } \\
\text { relevantes para a qualidade da formação oferecida }\end{array}$ & Lei específica \\
\hline & Crítica ao modelo de avaliação educacional atual & Diagnóstico \\
\hline Avaliação & $\begin{array}{l}\text { Propõe a transformação do sistema avaliativo atual em } \\
\text { um subsistema nacional de avaliação, vinculado a uma } \\
\text { dada concepção de qualidade educacional. }\end{array}$ & Meta novo PNE \\
\hline
\end{tabular}

Fonte: Brasil, CONAE 2010, Documento Final (tabulado pelos autores). GD= Gestão Democrática. 